Research Paper

\title{
MCMs expression in lung cancer: implication of prognostic significance
}

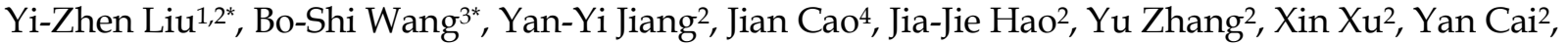 \\ Ming-Rong Wang ${ }^{2 凶}$ \\ 1. Department of Medical Oncology, Fudan University Shanghai Cancer Center; Department of Oncology, Shanghai Medical College, Fudan University, \\ Shanghai 200032, China; \\ 2. State Key Laboratory of Molecular Oncology, National Cancer Center/Cancer Hospital, Peking Union Medical College and Chinese Academy of Medical \\ Sciences, Beijing, China; \\ 3. State Key Laboratory of Oncogenes and Related Genes, Shanghai Cancer Institute, Renji Hospital, Shanghai Jiaotong University School of Medicine, \\ Shanghai, China; \\ 4. Department of Pathology, National Cancer Center/Cancer Hospital, Peking Union Medical College and Chinese Academy of Medical Sciences, Beijing, \\ China. \\ "These authors contributed equally to this work
}

$\square$ Corresponding author: Ming-Rong Wang, Ph.D., State Key Laboratory of Molecular Oncology, National Cancer Center/Cancer Hospital, PUMC, CAMS, 17 Panjiayuan Nanli, Chaoyang District, Beijing 100021, China. Tel.: +86-10-87788425. E-mail address: wangmr2015@cicams.ac.cn

(c) Ivyspring International Publisher. This is an open access article distributed under the terms of the Creative Commons Attribution (CC BY-NC) license (https:// creativecommons.org/licenses/by-nc/4.0/). See http://ivyspring.com/terms for full terms and conditions.

Received: 2017.04.27; Accepted: 2017.08.19; Published: 2017.10.09

\begin{abstract}
Minichromosome Maintenance (MCM) proteins play essential roles in various cancers. We previously reported that MCM7 could be a prognostic biomarker in non-small cell lung cancer (NSCLC). The purpose of current study is to explore roles of other MCM proteins in NSCLC and their correlation with clinico-pathologic parameters of NSCLC patients. We evaluated the expression of MCM2, MCM5 and MCM6 immunohistochemically in 571 primary NSCLC samples. High expression of MCM2, MCM5 and MCM6 was detected in $42.2 \%, 38.3 \%$ and $52.9 \%$ of tumor tissues, respectively. The expression of MCM2, MCM5 and MCM6 was significantly associated with gender $(P=0.00004,0.00004,0.008)$, tumor type $(P<0.00001,<0.00001,0.00001)$ and smoking history $(P=0.009,0.00043,0.002)$. MCM2 and MCM5 were detected more in central-type lung cancer $(P<0.006,0.016)$. Higher labeling index (LI) of MCM2 was observed more frequently in aged patients $(P=0.023)$ and in those at later stage $(P=0.001)$. Higher MCM5 Lls was detected more in patients with distant metastasis $(P=0.008)$. Kaplan-Meier curves indicated that early-stage (stage I/II) patients with higher MCM2 Lls had a poorer OS compared to those with lower Lls ( $P=$ 0.021 ). And lung squamous cell carcinoma (SCC) patients presenting high MCM5 expression had shorter OS $(P=0.015)$. Multivariate Cox regression analysis showed that MCM5 was an independent prognostic indicator $(P=0.035, \mathrm{HR}=1.586,95 \% \mathrm{Cl}$ : 1.032-2.437). We reported for the first time that higher MCM5 Lls could be an independent adverse prognostic biomarker for SCC patients.
\end{abstract}

Key words: Non-small cell lung cancer; Prognosis; Biomarker; MCM2; MCM5; MCM6

\section{Introduction}

Lung cancer is a highly lethal and extremely common cancer worldwide. In China, during the past 30 years, mortality from lung cancer has increased by 465\%[1]. Cancer Statistics 2017 reported that the overall 5-year survival rate of lung cancer patients was approximately $18 \%$ [2]. However, even at the same stage, the prognosis of patients varies a lot. Non-small cell lung cancer (NSCLC), of which squamous cell carcinoma (SCC) and adenocarcinoma (ADC) account for the vast majority of cases, represents almost $80 \%$ of primary lung cancer cases [3]. Nowadays, no robust biomarkers have been 
applied to clinical practice to provide prognostic evaluation of lung cancer. Minichromosome maintenance (MCM) proteins are essential components for DNA replication, and also prognostic markers for various human tumors. Our previous work has showed that MCM7 over-expression was an adverse marker for overall survival of NSCLC patients, even for early-stage ones [4]. In the present study, we evaluated the expression levels of MCM2, MCM5, MCM6 and their clinical significance in NSCLC.

\section{Materials and methods}

\section{Patients and samples}

A total of 571 surgically resected NSCLC tissues were collected at the Cancer Hospital, Chinese Academy of Medical Sciences and Peking Union Medical College (CAMS \& PUMC), in Beijing, China from 2005 to 2010. The tissue samples were collected shortly after radical surgery of NSCLC patients, among whom $402(70.4 \%)$ had early-stage disease (stage I-II) and included 209 SCCs and 193 ADCs. Primary tumor regions were excised by experienced pathologists. For construction of microarrays, tissues were routinely fixed with neutral buffered formalin ( $\mathrm{pH}$ 7.4) and paraffin-embedded. All the samples used in this study were residual specimens after diagnosis sampling. And all patients received no treatment before surgery and signed separate informed consent forms for sampling and research. This study was approved by the Ethics Committee/Institutional Review Board of the National Cancer Center/Cancer Hospital, PUMC/CAMS (No. 12-098/632). And all the methods in our study were carried out in accordance with the approved guidelines. Survival data were available with a median follow-up of 785 days (range 21 2,195 days). The clinico-pathologic characteristics of the patients are summarized in Table 1.

\section{Tissue microarrays construction and immunohistochemistry (IHC)}

The TMA was constructed as described previously. For each case, three cancer tissue cores (diameter $=1 \mathrm{~mm}$; height $=5 \mathrm{~mm}$ ) were taken from the primary block.

IHC was performed on the 4- $\mu \mathrm{m}$ sections of the resulting TMA block. The slides were deparaffinized, rehydrated, immersed in 3\% hydrogen peroxide solution for $15 \mathrm{~min}$, heated in citrate buffer ( $\mathrm{pH}$ 6.0) for $25 \mathrm{~min}$ at $95^{\circ} \mathrm{C}$, and cooled for $60 \mathrm{~min}$ at room temperature. In between each incubation step, sections were washed with PBS ( $\mathrm{pH} 7.4)$. The slides were blocked with 10\% normal goat serum for $30 \mathrm{~min}$ at $37^{\circ} \mathrm{C}$ and washed and incubated overnight at $4^{\circ} \mathrm{C}$ with mouse monoclonal antibody against MCM2 (1:200; 10513-1-AP, Proteintech Group, Inc. Chicago, IL, USA), MCM5 (1:200; 11703-1-AP, Proteintech Group, Inc. Chicago, IL, USA), or MCM6 (1:200; 13347-2-AP, Proteintech Group, Inc. Chicago, IL, USA). Slides with no primary antibodies added served as negative controls. After washing with PBS, the slides were visualized using the PV-9000 Polymer Detection System following the manufacturer's instructions (GBI, USA) and subsequently counterstained with hematoxylin.

Table 1. Baseline Characteristics of 571 Tissue Samples

\begin{tabular}{|c|c|}
\hline Variable & Value \\
\hline \multicolumn{2}{|l|}{ Age } \\
\hline Median & 61 \\
\hline Range & $31-84$ \\
\hline \multicolumn{2}{|l|}{ Sex } \\
\hline Male & 424 \\
\hline Female & 147 \\
\hline \multicolumn{2}{|l|}{ Tumor type } \\
\hline SCC & 293 \\
\hline ADC & 278 \\
\hline \multicolumn{2}{|l|}{ Tumor stage ${ }^{a}$} \\
\hline I & 182 \\
\hline II & 220 \\
\hline $\mathrm{III}+\mathrm{IV}$ & 169 \\
\hline \multicolumn{2}{|l|}{ T status } \\
\hline $\mathrm{T} 1$ & 71 \\
\hline $\mathrm{T} 2$ & 366 \\
\hline T3 & 95 \\
\hline $\mathrm{T} 4$ & 39 \\
\hline \multicolumn{2}{|l|}{ N status } \\
\hline No & 297 \\
\hline N1-3 & 274 \\
\hline \multicolumn{2}{|l|}{ M status } \\
\hline M0 & 560 \\
\hline M1 & 11 \\
\hline \multicolumn{2}{|l|}{ Tumor differentiation } \\
\hline Well & 30 \\
\hline Moderate & 260 \\
\hline Poorly & 281 \\
\hline \multicolumn{2}{|l|}{ Gross pathology } \\
\hline Central-type & 307 \\
\hline Peripheral-type & 264 \\
\hline \multicolumn{2}{|l|}{ Smoking status } \\
\hline Current or former smoker & 390 \\
\hline Nonsmoker & 78 \\
\hline \multicolumn{2}{|l|}{ Family historyb } \\
\hline Lung cancer & 48 \\
\hline No & 447 \\
\hline
\end{tabular}

\section{Immunohistochemical assessment}

The expression levels of MCM2, MCM5 and MCM6 were assessed by the labeling index (LI) determined by counting the number of distinctly stained malignant cells, regardless of the intensity, divided by the total number of tumor cells [5]. Proteins were evaluated in the areas of highest positivity and at least 1000 tumor cells were counted. 
The average of the percentage of positive cells in the three cores represented the final score of the sample, yielding a continuous score from 0 to 100 . All cases were divided into two groups, a strongly positive group (score range: $50-100$ ) and a low/no expression group (score range: 0-50). Assessment and imaging of IHC was performed using a Leica DM2000 microscope equipped with Leica DFC Cameras-Image Acquisition System (software V3.5.0, Switzerland).

\section{Statistical analysis}

All analyses were performed using PASW Statistics 18 (SPSS Inc., Chicago). Associations between protein expression and clinico-pathologic parameters were assessed by the Mann-Whitney test and the Kruskal-Wallis test. For survival analyses, Kaplan-Meier survival curves were constructed, and differences were tested by the log-rank test. Overall survival was defined as the time between the date of surgery and the date of death from lung cancer or the date of last contact. The data of patients alive at the end of the study were censored. Multiple Cox proportional hazards regression (backward, stepwise) was performed to identify the independent factors with a significant impact on patient survival. The hazard ratios (HRs) and 95\% confidence intervals of the prognostic factors were calculated. All $P$ values were two-sided, and the results were considered significant if $P<0.05$.
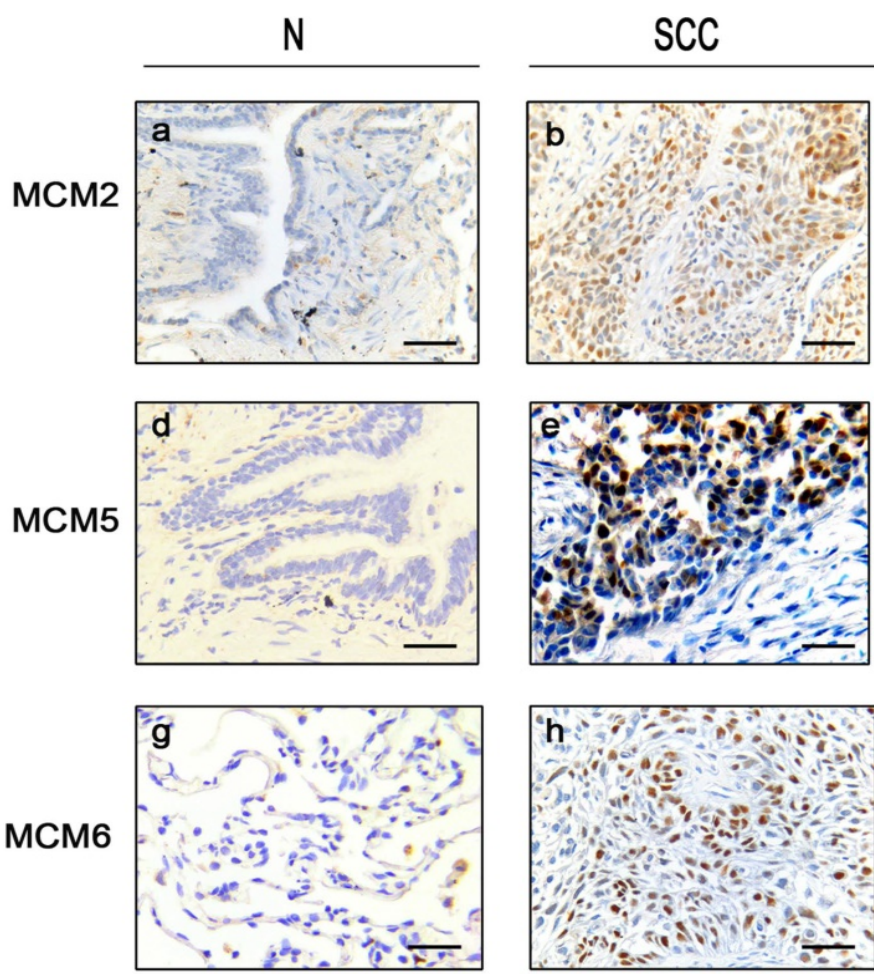

Figure 1. Expression status of MCM2, MCM5 and MCM6 in NSCLC tissue samples Representative immunohistochemical microphotographs of MCM2 (a,b,c), MCM5 (d,e,f) and MCM6 (g,h,i) with high (positive) and low (negative) expression in NSCLC and their adjacent non-malignant tissues. The subtypes are SCCs (b, e, h) and ADCs (c, f, i). Bar $=100 \mu \mathrm{m}$.
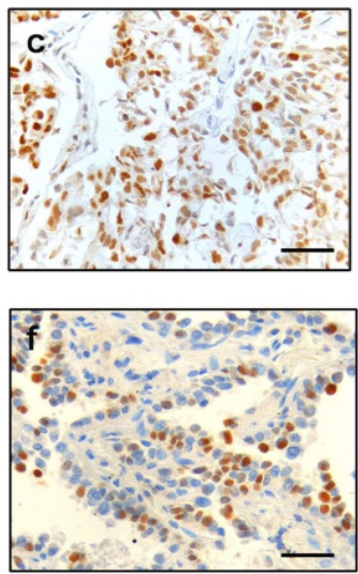

\section{Analysis of TCGA lung cancer datasets}

The NSCLC datasets were acquired from The UCSC Cancer Browser (https://genome-cancer. ucsc.edu/proj/site/hgHeatmap/). The dataset IDs were TCGA_LUSC_exp_HiSeqV2_PANCAN (N=553) and TCGA_LUAD_exp_HiSeqV2_PANCAN (N=571). Differences between the relative gene expression levels in NSCLC (ADC or SCC) and non-tumor tissues (N) were analyzed using students $t$-test. The correlation of mRNA levels of MCM2, MCM5 and MCM6 with OS in TCGA database was examined through SurvExpress[6] (http://bioinformatica.mty. itesm.mx/SurvExpress). The selected lung cancer databases were LUAD - TCGA - Lung adenocarcinoma June $2016(\mathrm{~N}=475)$ and LUSC TCGA - Lung squamous cell carcinoma June 2016 $(\mathrm{N}=175)$.

\section{Results}

\section{Protein expression in tissue samples}

In tumor tissues, MCM2 and MCM5 displayed higher expression (score 50-100) in 234 (148 SCCs and 86 ADCs) and 214 cases (143 SCCs and 71 ADCs), respectively. MCM6 was highly expressed in 173 SCCs and 118 ADCs. All three proteins showed nuclear staining (Fig. 1).

\section{Relationships between protein expression and clinico-pathologic features}

The high expression of MCM2, MCM5 and MCM6 was associated with gender $(P=0.00004$, $0.00004,0.008)$, tumor type $(P<0.00001,<$ $0.00001, \quad 0.00001)$ and smoking history $(P=$ $0.009, \quad 0.00043, \quad 0.002)$. MCM2 and MCM5 were detected more in central-type lung cancer $(P<0.006,0.016)$. Higher MCM2 LIs was observed more frequently in aged ones $(\geq 60$ years old) $(P=$ 0.023 ) and in patients at later stage (stage III/IV) $(P=0.001)$. Higher MCM5 LIs was significantly associated with patients with distant metastasis ( $P$ $=0.008)$ (Table 2$)$. 
A

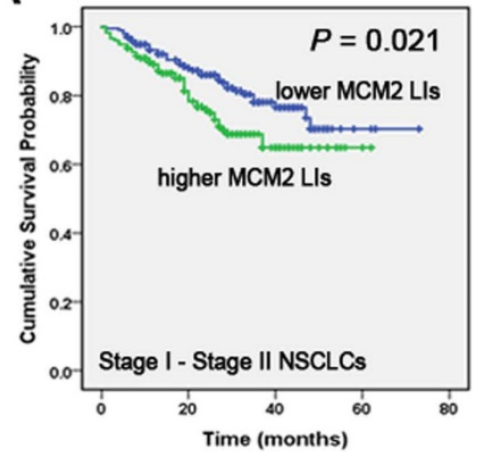

B

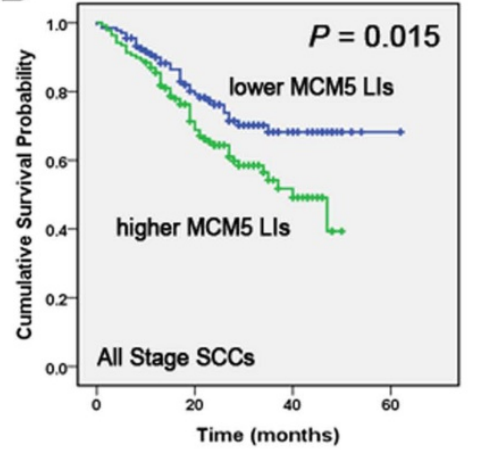

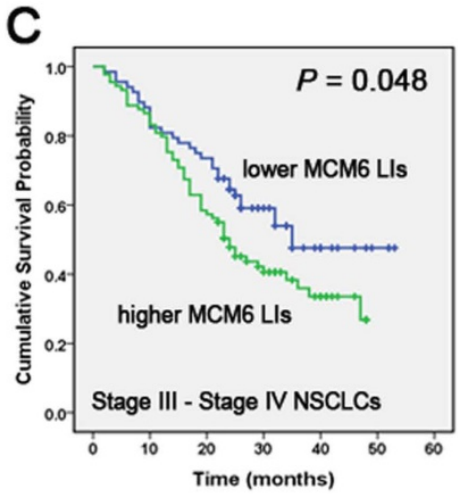

Figure 2. Correlation of MCM2, MCM5 and MCM6 LIs with NSCLC patients' overall survival (OS) Kaplan-Meier curves showing the association between LIs of MCM2 (A), MCM5 (B), MCM6 (C) and OS in different stages and in different histological tumor types in tissue samples. All the $P$ values are shown in the graph, by log-rank test.

Table 2. Relationship Between Protein Overexpression and Clinicopathologic Parameters

\begin{tabular}{|c|c|c|c|c|}
\hline Parameter & $\begin{array}{l}\text { No. of } \\
\text { patients }\end{array}$ & MCM2(\%) & MCM5(\%) & MCM6(\%) \\
\hline \multicolumn{5}{|l|}{ Gender } \\
\hline Male & 424 & $47.3 \%(195 / 412)$ & $43.3 \%(180 / 416)$ & $56.2 \%(231 / 411)$ \\
\hline Female & 147 & $27.5(39 / 142)$ & $23.8(34 / 143)$ & $43.2(60 / 139)$ \\
\hline$P$-value & & 0.00004 & 0.00004 & 0.008 \\
\hline \multicolumn{5}{|l|}{ Age } \\
\hline$\geq 60$ & 314 & $46.6 \%(142 / 305)$ & $40.3 \%(123 / 305)$ & $53.8 \%(162 / 301)$ \\
\hline$<60$ & 257 & $36.9(92 / 249)$ & $35.8(91 / 254)$ & $51.8 \%(129 / 249)$ \\
\hline$P$-value & & 0.023 & 0.276 & 0.638 \\
\hline \multicolumn{5}{|l|}{ Tumor type } \\
\hline SCC & 293 & $52.5 \%(148 / 282)$ & $49.8 \%(143 / 287)$ & $62.2 \%(173 / 278)$ \\
\hline $\mathrm{ADC}$ & 278 & $31.6(86 / 272)$ & $26.1(71 / 272)$ & $43.4 \%(118 / 272)$ \\
\hline$P$-value ${ }^{a}$ & & $<0.00001$ & $<0.00001$ & 0.00001 \\
\hline \multicolumn{5}{|l|}{ Gross pathology } \\
\hline Central-type & 307 & $47.6 \%(140 / 294)$ & $42.9 \%(129 / 301)$ & $54.4 \%(161 / 296)$ \\
\hline Peripheral-type & 264 & $36.2(94 / 260)$ & $32.9(85 / 258)$ & $51.2 \%(130 / 254)$ \\
\hline$P$-value ${ }^{a}$ & & 0.006 & 0.016 & 0.452 \\
\hline \multicolumn{5}{|c|}{ Tumor differentiation } \\
\hline Well / Moderate & 290 & $43.2 \%(120 / 278)$ & $39.5 \%(111 / 281)$ & $54.2 \%(149 / 275)$ \\
\hline Poorly & 281 & $41.5 \%(114 / 275)$ & $37.2 \%(103 / 277)$ & $51.8 \%(142 / 274)$ \\
\hline$P$-value & & 0.684 & 0.573 & 0.58 \\
\hline \multicolumn{5}{|l|}{ Stage } \\
\hline I-II & 402 & $47.6 \%(185 / 389)$ & $39.9 \%(158 / 396)$ & $51.6 \%(199 / 386)$ \\
\hline $\mathrm{III}+\mathrm{IV}$ & 169 & $29.7(49 / 165)$ & $34.4(56 / 163)$ & $56.1(92 / 164)$ \\
\hline$P$-value ${ }^{a}$ & & 0.0001 & 0.22 & 0.329 \\
\hline \multicolumn{5}{|l|}{ Tumor size } \\
\hline $\mathrm{T} 1$ & 71 & $49.3(35 / 71)$ & $44.9(31 / 69)$ & $59.4(41 / 69)$ \\
\hline $\mathrm{T} 2$ & 366 & $42.8 \%(151 / 353)$ & $36.5 \%(131 / 359)$ & $51.0 \%(178 / 349)$ \\
\hline $\mathrm{T} 3$ & 95 & $37.0(34 / 92)$ & $41.5(39 / 94)$ & $55.3(52 / 94)$ \\
\hline $\mathrm{T} 4$ & 39 & $36.8(14 / 38)$ & $35.1(13 / 37)$ & $52.6(20 / 38)$ \\
\hline$P$-value ${ }^{b}$ & & 0.392 & 0.505 & 0.593 \\
\hline \multicolumn{5}{|c|}{ Lymph node metastasis } \\
\hline No & 297 & $40.8 \%(118 / 289)$ & $38.1 \%(111 / 291)$ & $54.8 \%(155 / 283)$ \\
\hline N1-3 & 274 & $43.8 \%(116 / 265)$ & $38.4 \%(103 / 268)$ & $50.9 \%(136 / 267)$ \\
\hline$P$-value ${ }^{a}$ & & 0.484 & 0.944 & 0.368 \\
\hline \multicolumn{5}{|l|}{ Distant metastasis } \\
\hline M0 & 560 & $42.7 \%(232 / 543)$ & $39.1 \%(214 / 548)$ & $53.2 \%(287 / 539)$ \\
\hline M1 & 11 & $18.2(2 / 11)$ & $0(0 / 11)$ & $36.4(4 / 11)$ \\
\hline$P$-value ${ }^{\mathrm{a}}$ & & 0.103 & 0.008 & 0.267 \\
\hline \multicolumn{5}{|l|}{ Smoking history } \\
\hline Nonsmoker & 78 & $30.8(24 / 78)$ & $22.7(17 / 75)$ & $37.3(28 / 75)$ \\
\hline $\begin{array}{l}\text { Current or former } \\
\text { smoker }\end{array}$ & 390 & $46.8 \%(177 / 378)$ & $44.5 \%(171 / 384)$ & $57.2 \%(215 / 376)$ \\
\hline$P$-value & & 0.009 & 0.00043 & 0.002 \\
\hline \multicolumn{5}{|l|}{ Family history } \\
\hline Lung cancer & 48 & $42.6(20 / 47)$ & $35.4(17 / 48)$ & $42.6(20 / 47)$ \\
\hline No & 447 & $40.6 \%(176 / 434)$ & $37.8 \%(165 / 437)$ & $53.1 \%(229 / 432)$ \\
\hline$P$-value ${ }^{a}$ & & 0.791 & 0.751 & 0.168 \\
\hline
\end{tabular}

Table 3. Univariate and multivariate analysis of survival in patients with squamous cell carcinoma

\begin{tabular}{|c|c|c|c|c|c|c|}
\hline \multirow[t]{2}{*}{ Variable } & \multicolumn{3}{|c|}{ Univariate Analysis } & \multicolumn{3}{|c|}{ Multivariate Analysis } \\
\hline & HR & $95 \% \mathrm{CI}$ & $\mathrm{P}$ & HR & $95 \% \mathrm{CI}$ & $\mathrm{P}$ \\
\hline \multicolumn{7}{|l|}{ MCM5 } \\
\hline High vs. low LIs & 1.679 & $1.095-2.573$ & 0.017 & 1.586 & $1.032-2.437$ & 0.035 \\
\hline \multicolumn{7}{|l|}{ Age } \\
\hline$\geq 60$ vs. $<60$ & 1.275 & $0.837-1.943$ & 0.258 & & & \\
\hline \multicolumn{7}{|l|}{ Gender } \\
\hline Male vs. female & 1.341 & $0.649-2.769$ & 0.428 & & & \\
\hline \multicolumn{7}{|l|}{ Stage } \\
\hline Stage I-II vs. Stage II-IV & 2.136 & $1.424-3.206$ & 0.00025 & 1.508 & $0.809-2.814$ & 0.196 \\
\hline \multicolumn{7}{|l|}{$\mathrm{T}$ status } \\
\hline$\leq 7 \mathrm{~cm}$ vs. $>7 \mathrm{~cm}$ & 1.753 & $1.156-2.657$ & 0.008 & 1.262 & $0.753-2.114$ & 0.377 \\
\hline \multicolumn{7}{|l|}{ N status } \\
\hline N0 vs. N1-3 & 1.841 & $1.216-2.787$ & 0.004 & 1.301 & $0.753-2.249$ & 0.346 \\
\hline \multicolumn{7}{|l|}{ Tumor differentiation } \\
\hline $\begin{array}{l}\text { Well vs. Moderate vs. } \\
\text { poorly }\end{array}$ & 0.805 & $0.535-1.210$ & 0.296 & & & \\
\hline \multicolumn{7}{|l|}{ Location } \\
\hline Central vs. peripheral & 0.784 & $0.506-1.214$ & 0.275 & & & \\
\hline \multicolumn{7}{|l|}{ Smoking history } \\
\hline $\begin{array}{l}\text { Non vs. current or former } \\
\text { smoker }\end{array}$ & 2.233 & $0.549-9.087$ & 0.262 & & & \\
\hline \multicolumn{7}{|l|}{ Family history } \\
\hline $\begin{array}{l}\text { Lung cancer vs. no family } \\
\text { history }\end{array}$ & 1.877 & $0.901-3.908$ & 0.093 & & & \\
\hline
\end{tabular}

HR = Hazard Ratio.

\section{The impact of protein expression on overall survival (OS)}

In tissue samples, Kaplan-Meier analysis indicated that early-stage (stage I/II) patients with higher MCM2 LIs had a lower OS compared to those with lower LIs of the protein $(P=0.021)$. In late-stage patients, MCM6 overexpression was correlated with a poor overall survival $(P=0.048)$. Considering the different histological tumor types, the OS of the higher MCM5 LIs group was poorer than that of the lower MCM5 LIs group in SCCs for all stages $(P=$ 0.015) (Fig. 2). 


\section{Effect of protein expression on survival by Cox regression analysis}

In SCC patients, univariate Cox regression analyses of the prognostic significance showed that higher MCM5 LIs was significantly associated with an elevated risk of death compared to low expression of the protein $(P=0.017, \mathrm{HR}=1.679,95 \% \mathrm{CI}: 1.095$ 2.573). Late-stage patients $(P=0.00025)$, tumor size $>7$ $(P=0.008)$ and lymph node metastasis $(P=0.004)$ were also contribute factors to shorter OS of patients. Multivariate Cox proportional hazards model indicated that MCM5 was an independent prognostic factor in tumor tissues as compared with stage, tumor size and N-status $(P=0.035, \mathrm{HR}=1.586,95 \% \mathrm{CI}$ : 1.032-2.437, Table 3).

\section{Transcript levels of MCM2, MCM5 and MCM6 in NSCLC tissues and correlation with OS}

To further delineate the mRNA expression of MCM2, MCM5 and MCM6 in NSCLC tissue samples. We compared the relative expression levels of the indicated genes between non-tumoral and NSCLC samples in two TCGA lung cancer datasets. The resutls showed the overexpression of MCM2, MCM5 and MCM6 in both ADC and SCC tissue samples (Fig. $3)$. Moreover, to test the asscociation between mRNA expression levels of the investigated MCM family genes and OS of NSCLC patients, we also explored Survexpress to analyze TCGA lung cancer datasets. The results indicated that the higher expression of MCM2, MCM5 and MCM6 mRNAs in both ADCs and SCCs predicated the shorter OS of the patients (Fig. 4).

\section{TCGA-LUSC}
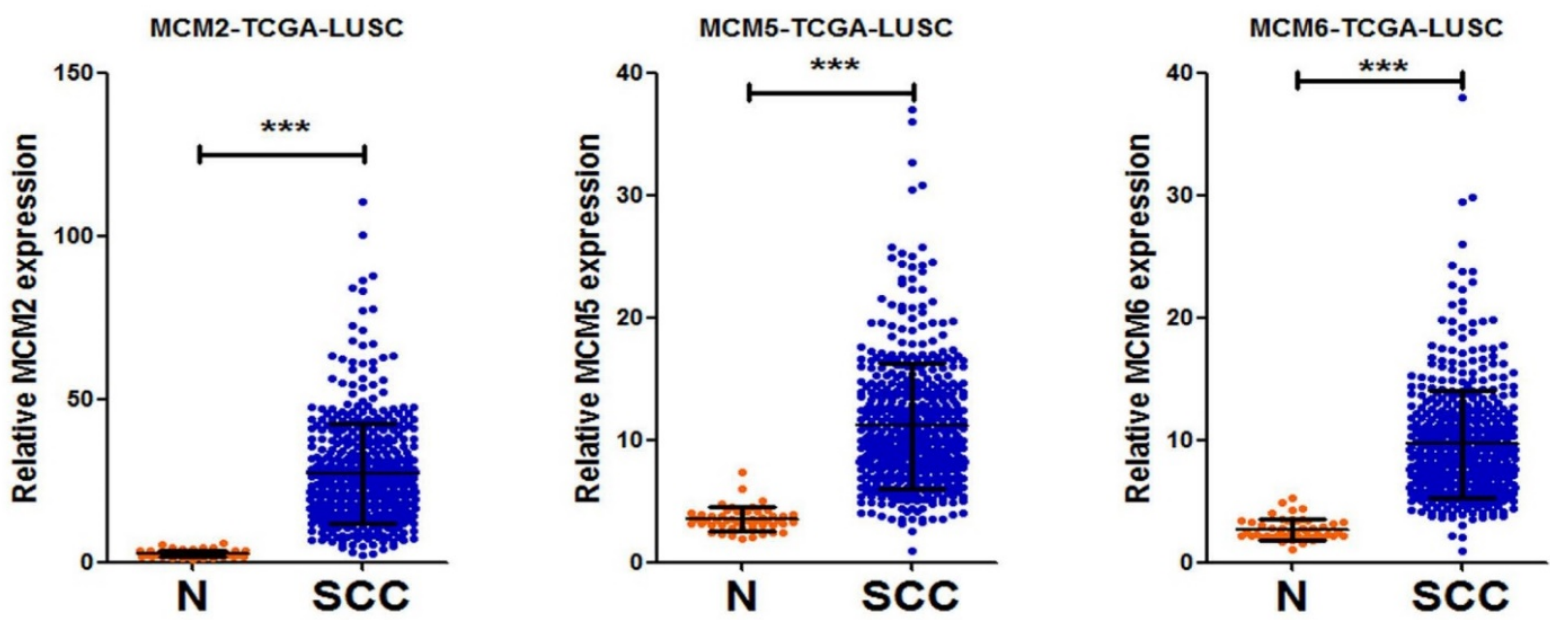

\section{TCGA-LUAD}
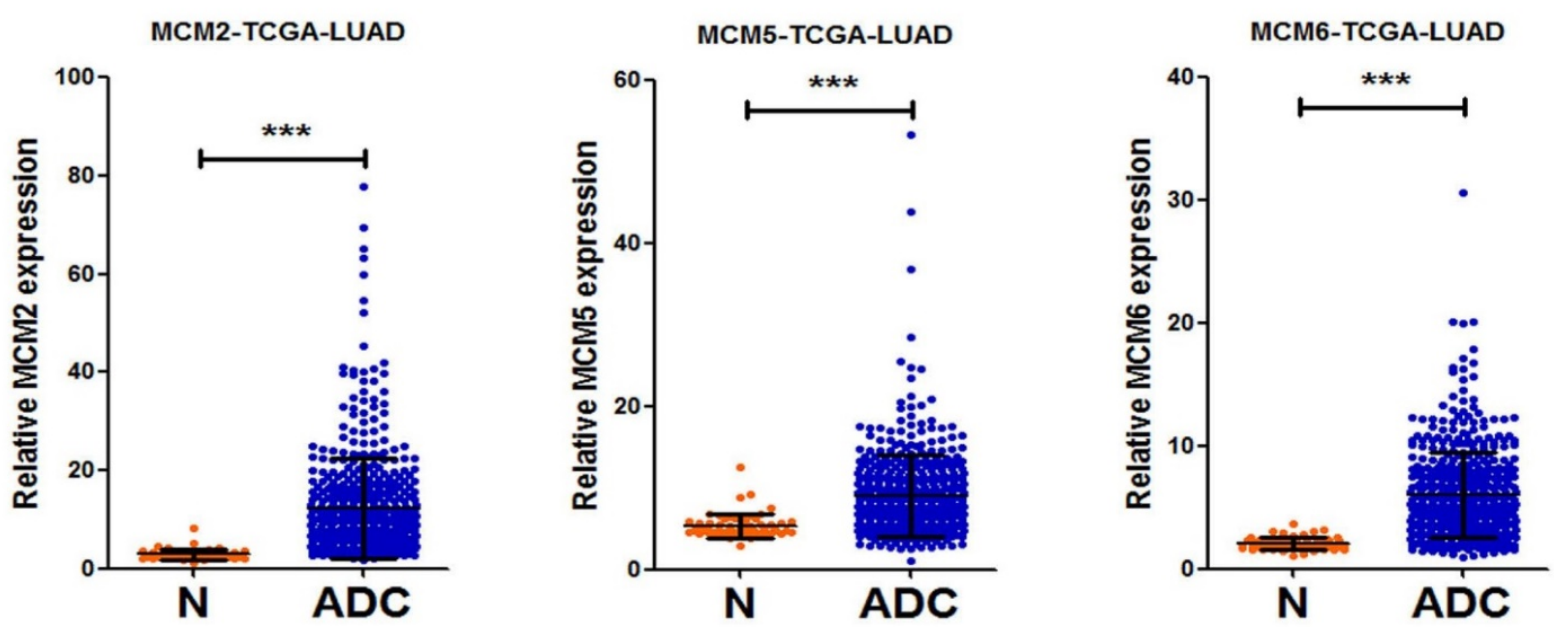

Figure 3. Overexpression of MCM2, MCM5 and MCM6 mRNAs in NSCLC samples Transcript levels of MCM2, MCM5 and MCM6 in non-tumor tissues $(\mathrm{N})$ and NSCLC tissues (SCCs or ADCs) from TCGA LUSC $(\mathrm{N}=553)$ and TCGA LUAD ( $N=571)$ datasets. Data are represented as mean \pm SD. All $P$ values were calculated by t-test analysis, $* * * P<0.001$. 
TCGA - Lung adenocarcinoma June 2016

MCM2

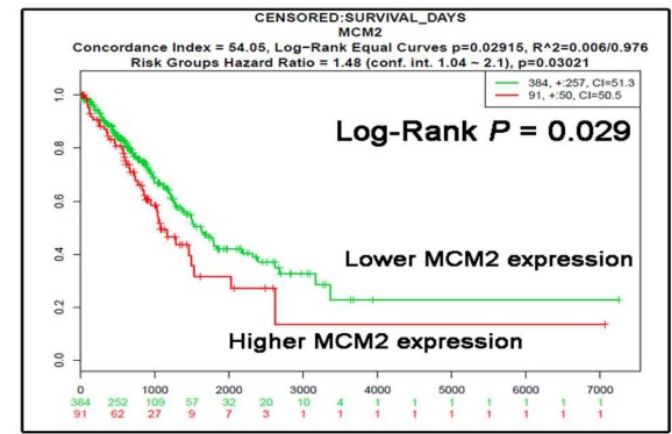

MCM5

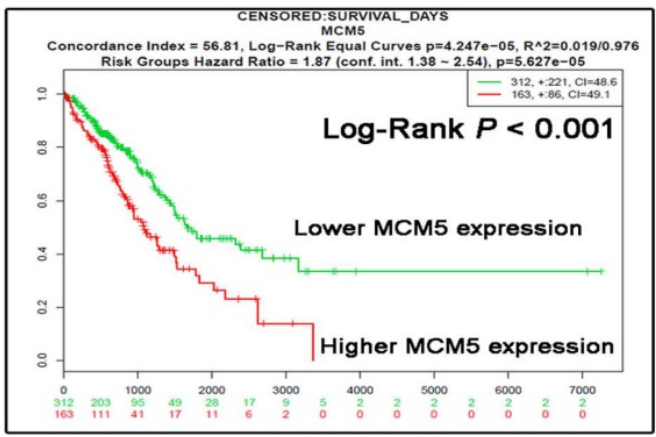

MCM6

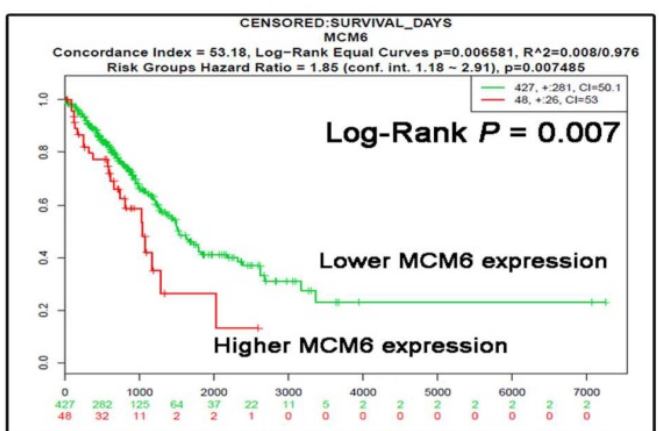

TCGA - Lung squamous cell carcinoma June 2016
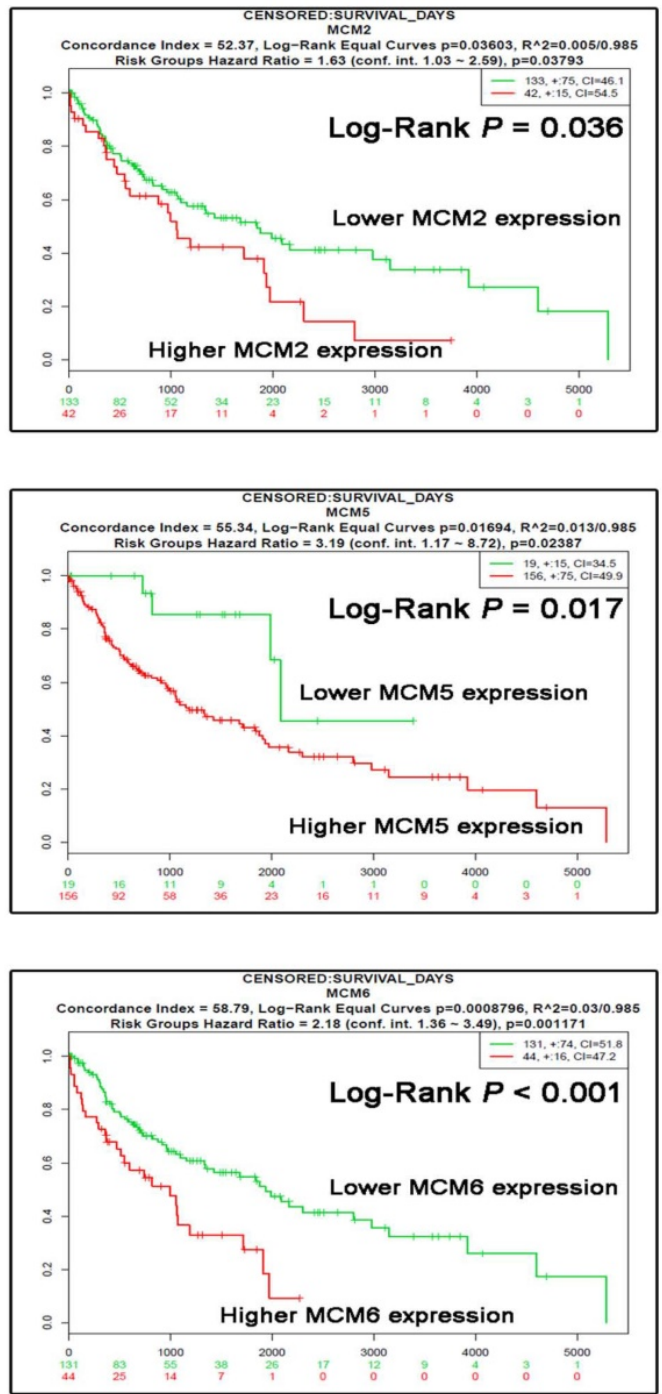

Figure 4. Correlation of MCM2, MCM5 and MCM6 mRNAs with patients' overall survival (OS) in TCGA database.The survival analysis stratified by MCM2, MCM5 and MCM6 expression levels in datasets LUAD - TCGA - Lung adenocarcinoma June $2016(\mathrm{~N}=475)$ and LUSC - TCGA - Lung squamous cell carcinoma June $2016(\mathrm{~N}=175)$ were analyzed using the Survexpress online platforms. The Log-Rank $P$ values are shown in the graph.

\section{Discussion}

The minichromosome maintenance (or MCM) protein family is composed of six related proteins that are conserved in all eukaryotes. Many experiments indicate that the MCMs are central players in multiple aspects of genome stability, such as regulation of transcription, chromatin remodeling and checkpoint responses [7-9].

MCM proteins can act as biological markers of dysplasia and malignancy [10]. Various studies show that MCM proteins are also prognostic markers for many types of human tumors, including gliomas, prostate cancer, cervical cancer, breast cancer, renal cell carcinoma, colorectal cancer and lung cancer [11-16]. In lung cancer, higher levels of MCM2 were associated with a non-significant increased risk of death [17]. It was also reported to act as a novel therapeutic target of lovastatin treatment in NSCLCs [18]. High MCM3 expression was reported to have association with poor prognosis in medulloblastoma and glioma [16, 19], and showed high expression in carcinomas of colon, cervix, stomach, kidney, breast, but not in lung cancer [20]. MCM4 expression was not associated with survival in non-small cell lung cancer patients [21].

In our current study, MCM2, MCM6 could act as an adverse prognostic biomarker, which was in consistent with previous report $[5,22]$. Overexpression of MCM5 protein has been found to be significantly associated with the progression and prognosis of several human cancers, such as breast 
cancer [23], colorectal cancer, and oral squamous cell carcinoma [24]. MCM5 may predict and diagnose bladder cancer recurrence [25]. Also, MCM5 may serve as a potential therapeutic target for bladder cancer [26]. Here we reported for the first time that MCM5 could act as a potential prognostic biomarker in SCC, which lacks therapeutic approaches in advanced stage.

We previously found that MCM7 was detected significantly higher in SCCs $(P=0.0007)$, male patients $(P=0.0065)$, poorly differentiated tumors $(P$ $=0.0120)$ and current or former smokers $(P=0.0007)$. The current study showed that MCM2, MCM5 and MCM6 were of significantly high expression in patients with smoking history, male and SCCs. MCM2 and MCM5 were detected more in central-type lung cancer. As we known, squamous cell carcinomas are often centrally located, and male patients were more likely to have smoking history, which may explain our results.

In summary, our data revealed that MCM5 may be an independent prognostic factor in patients with SCC, to which further validation studies are needed.

\section{Abbreviations}

MCM: Minichromosome maintenance; NSCLC: non-small cell lung cancer; SCC: squamous cell carcinoma; ADC: adenocarcinoma; LI: labeling index; IHC: immunohistochemistry; OS: overall survival; TCGA: The Cancer Genome Atlas.

\section{Acknowledgments}

This work was supported by Special Public Health Fund of China (201402003), National Key Technologies R\&D Program of China (2014BAI09B01), CAMS Innovation Fund for Medical Sciences (2016-I2M-1-001), National Science Fund (81702259), Shanghai Municipal Commission of Health and Family Planning Fund (20174Y0075), and Fudan University Shanghai Cancer Center Fund (YJ201508).

\section{Competing Interests}

The authors have declared that no competing interest exists.

\section{References}

1. Wen C, Dehnel T. China wrestles with lung cancer. The Lancet Oncology. 2011; 12: 15.

2. Siegel RL, Miller KD, Jemal A. Cancer Statistics, 2017. CA: a cancer journal for clinicians. 2017; 67: 7-30

3. Herbst RS, Heymach JV, Lippman SM. Lung cancer. N Engl J Med. 2008; 359: 1367-80.

4. Liu YZ, Jiang YY, Hao JJ, Lu SS, Zhang TT, Shang L, et al. Prognostic significance of MCM7 expression in the bronchial brushings of patients with non-small cell lung cancer (NSCLC). Lung cancer. 2012; 77: 176-82.

5. Ramnath N, Hernandez FJ, Tan DF, Huberman JA, Natarajan N, Beck AF, et al. MCM2 is an independent predictor of survival in patients with non-small-cell lung cancer. Journal of clinical oncology : official journal of the American Society of Clinical Oncology. 2001; 19: 4259-66.
6. Aguirre-Gamboa R, Gomez-Rueda H, Martinez-Ledesma E, Martinez-Torteya A, Chacolla-Huaringa R, Rodriguez-Barrientos A, et al. SurvExpress: an online biomarker validation tool and database for cancer gene expression data using survival analysis. PloS one. 2013; 8: e74250.

7. Forsburg SL. Eukaryotic MCM proteins: beyond replication initiation. Microbiology and molecular biology reviews : MMBR. 2004; 68: 109-31.

8. Vijayraghavan S, Schwacha A. The eukaryotic Mcm2-7 replicative helicase. Sub-cellular biochemistry. 2012; 62: 113-34.

9. Simon NE, Schwacha A. The Mcm2-7 replicative helicase: a promising chemotherapeutic target. BioMed research international. 2014; 2014: 549719.

10. Freeman A, Morris LS, Mills AD, Stoeber K, Laskey RA, Williams GH, et al. Minichromosome maintenance proteins as biological markers of dysplasia and malignancy. Clinical cancer research : an official journal of the American Association for Cancer Research. 1999; 5: 2121-32

11. Nishihara K, Shomori K, Fujioka S, Tokuyasu N, Inaba A, Osaki M, et al. Minichromosome maintenance protein 7 in colorectal cancer: implication of prognostic significance. International journal of oncology. 2008; 33: 245-51.

12. Gonzalez MA, Pinder SE, Callagy G, Vowler SL, Morris LS, Bird K, et al. Minichromosome maintenance protein 2 is a strong independent prognostic marker in breast cancer. Journal of clinical oncology : official journal of the American Society of Clinical Oncology. 2003; 21: 4306-13.

13. Brake T, Connor JP, Petereit DG, Lambert PF. Comparative analysis of cervical cancer in women and in a human papillomavirus-transgenic mouse model: identification of minichromosome maintenance protein 7 as an informative biomarker for human cervical cancer. Cancer research. 2003; 63: 8173-80.

14. Dudderidge TJ, McCracken SR, Loddo M, Fanshawe TR, Kelly JD, Neal DE, et al. Mitogenic growth signalling, DNA replication licensing, and survival are linked in prostate cancer. British journal of cancer. 2007; 96: 1384-93.

15. Dudderidge TJ, Stoeber K, Loddo M, Atkinson G, Fanshawe T, Griffiths DF, et al. Mcm2, Geminin, and KI67 define proliferative state and are prognostic markers in renal cell carcinoma. Clinical cancer research : an official journal of the American Association for Cancer Research. 2005; 11: 2510-7.

16. Hua C, Zhao G, Li Y, Bie L. Minichromosome Maintenance (MCM) Family as potential diagnostic and prognostic tumor markers for human gliomas. BMC cancer. 2014; 14: 526.

17. Yang J, Ramnath N, Moysich KB, Asch HL, Swede H, Alrawi SJ, et al. Prognostic significance of MCM2, Ki-67 and gelsolin in non-small cell lung cancer. BMC cancer. 2006; 6: 203.

18. Zhang $\mathrm{X}$, Teng $\mathrm{Y}$, Yang $\mathrm{F}$, Wang $\mathrm{M}$, Hong $\mathrm{X}$, Ye LG, et al. MCM2 is a therapeutic target of lovastatin in human non-small cell lung carcinomas. Oncology reports. 2015; 33: 2599-605.

19. Lau KM, Chan QK, Pang JC, Li KK, Yeung WW, Chung NY, et al. Minichromosome maintenance proteins 2, 3 and 7 in medulloblastoma: overexpression and involvement in regulation of cell migration and invasion. Oncogene. 2010; 29: 5475-89.

20. Ha SA, Shin SM, Namkoong H, Lee H, Cho GW, Hur SY, et al. Cancer-associated expression of minichromosome maintenance 3 gene in several human cancers and its involvement in tumorigenesis. Clinical cancer research : an official journal of the American Association for Cancer Research. 2004; 10: 8386-95.

21. Kikuchi J, Kinoshita I, Shimizu Y, Kikuchi E, Takeda K, Aburatani H, et al. Minichromosome maintenance (MCM) protein 4 as a marker for proliferation and its clinical and clinicopathological significance in non-small cell lung cancer. Lung cancer. 2011; 72: 229-37.

22. Vigouroux C, Casse JM, Battaglia-Hsu SF, Brochin L, Luc A, Paris C, et al. Methyl(R217)HuR and MCM6 are inversely correlated and are prognostic markers in non small cell lung carcinoma. Lung cancer. 2015; 89: 189-96.

23. Eissa S, Matboli $\mathrm{M}$, Shehata $\mathrm{HH}$, Essawy NO. MicroRNA-10b and minichromosome maintenance complex component 5 gene as prognostic biomarkers in breast cancer. Tumour biology : the journal of the International Society for Oncodevelopmental Biology and Medicine. 2015; 36: 4487-94.

24. Yu SY, Wang YP, Chang JY, Shen WR, Chen HM, Chiang CP. Increased expression of MCM5 is significantly associated with aggressive progression and poor prognosis of oral squamous cell carcinoma. Journal of oral pathology \& medicine : official publication of the International Association of Oral Pathologists and the American Academy of Oral Pathology. 2014; 43: 344-9.

25. Brems-Eskildsen AS, Zieger K, Toldbod H, Holcomb C, Higuchi R, Mansilla F, et al. Prediction and diagnosis of bladder cancer recurrence based on urinary content of hTERT, SENP1, PPP1CA, and MCM5 transcripts. BMC cancer. 2010; 10: 646 .

26. Hsu I, Chuang KL, Slavin S, Da J, Lim WX, Pang ST, et al. Suppression of ERbeta signaling via ERbeta knockout or antagonist protects against bladder cancer development. Carcinogenesis. 2014; 35: 651-61. 